Title: Adaptive mechanism of Echinochloa crus-galli Beauv. var. formosensis Ohwi under salt stress: Effect of salicylic acid on salt sensitivity

\title{
Authors' name:
}

Hiroko Sawada ${ }^{1,}$, Ie-Sung Shim ${ }^{2}$, Kenji Usui ${ }^{1}$, Katsuichiro Kobayashi ${ }^{1}$ and Shinsuke Fujihara ${ }^{1,3}$

${ }^{1}$ Graduate School of Life and Environmental Sciences, University of Tsukuba, Ibaraki, 305-8572, Japan; ${ }^{2}$ Department of Environmental Horticulture, University of Seoul, Seoul, 130-743, Korea; ${ }^{3}$ Research Team for Soil and Plant Analysis, National Agricultural Research Center, Tsukuba, Ibaraki, 305-8666, Japan

\section{Name and address for correspondence:}

*Hiroko Sawada

Research Team for Soil and Plant Analysis, National Agricultural Research Center,

3-1-1 Kannondai, Tsukuba, Ibaraki, 305-8666, Japan

Telephone \& Fax: +81-29-838-8814

E-mail: hiros216@affrc.go.jp

Abbreviations: APX, ascorbate peroxidase; CAT, catalase; GR, glutathione reductase; ROS, reactive oxygen species; SA, salicylic acid; SOD; superoxide dismutase; $\Phi_{\mathrm{PSII}}$, efficiency of photosystem II photochemistry 


\begin{abstract}
Our previous study revealed that salicylic acid (SA) accumulates in salt-stressed rice (Oryza sativa L. cv. Nipponbare) seedlings, and we hypothesized that the accumulation of SA might potentiate oxidative injury in rice seedlings since the inhibition of SA synthesis alleviated the growth inhibition under high salinity. To further clarify the action of SA under salt stress, we investigated the changes in the SA content, the activities of the antioxidative enzymes, and the effects of exogenous SA on barnyardgrass (Echinochloa crus-galli Beauv. var. formosensis Ohwi), a gramineous weed which shows lower SA content and is more salt tolerant than rice. In E. crus-galli seedlings exposed to high salinity, neither free nor conjugated SA content showed any increase, while the fresh weight of the shoot and chlorophyll fluorescence $\left(\Phi_{\mathrm{PSII}}\right)$ slightly decreased. When E. crus-galli seedlings were treated with salt after foliar application of SA, the absorbed SA resulted in the enhancement of the salt-induced growth inhibition and a striking reduction of the $\Phi_{\text {PSII }}$ value. Catalase (CAT) and superoxide dismutase (SOD) activities of E. crus-galli seedlings were induced by the salt treatment. However, SA pre-treatment suppressed such an induction of CAT activity and further promoted SOD activity, both of which led to the elevation of the leaf hydrogen peroxide $\left(\mathrm{H}_{2} \mathrm{O}_{2}\right)$ level. The present results suggested that enlargement of the cellular SA pool facilitates the generation of $\mathrm{H}_{2} \mathrm{O}_{2}$ through the suppression of CAT activity and through a remarkable promotion of SOD activity, and thereby enhances the oxidative injury caused by salt stress.
\end{abstract}

Key words: Catalase; Echinochloa crus-galli; Hydrogen peroxide; Oxidative stress; Salicylic acid; Salt stress 


\section{Introduction}

Salicylic acid (SA) is a signal molecule that induces the plant defense response to pathogen attacks. It develops systemic acquired resistance (SAR), which results in a long-lasting, nonspecific, systemic resistance to subsequent pathogen infections [1]. It has been shown that endogenous SA content increases dramatically not only due to pathogen infection, but also to environmental stressors such as ozone, low temperature, and salinity [2-4]. SA has been suggested to be physiologically important in stress tolerance since exogenous SA brought about plants' tolerance to various abiotic stresses including chilling, drought, and salt [5-8]. In contrast, high levels of SA are known to potentiate the oxidative damage caused by $\mathrm{O}_{3}$ exposure and chilling temperature $[4,9]$. It was also reported that pre-treatment with SA, which elevates the chilling tolerance in maize, causes an increased sensitivity to drought in maize and wheat [10]. Thus, under different abiotic stresses or in different plant species, SA has been reported to show apparently contrasting effects, i.e. either the reduction or promotion of stress tolerance.

Our previous study [11] using rice seedlings showed that the activity of benzoic acid 2-hydroxylase (BA2H), which catalyses SA biosynthesis, was induced by salinity, and increases in this activity paralleled the accumulation of free SA. Furthermore, we observed that the suppression of SA accumulation restored the seedlings' growth under salinity, suggesting that the accumulation of endogenous SA relates to salt stress-induced injury in rice seedlings [11]. The serious damage caused by salt stress is at least partially due to the generation of reactive oxygen species (ROS), such as superoxide $\left(\mathrm{O}_{2}{ }^{-}{ }^{-}\right)$and hydrogen peroxide $\left(\mathrm{H}_{2} \mathrm{O}_{2}\right)$. SA could cause the inactivation of $\mathrm{H}_{2} \mathrm{O}_{2}$-removing enzymes $[12,13]$. In salt-stressed rice, decreases in the activity of catalase (CAT), a major $\mathrm{H}_{2} \mathrm{O}_{2}$-scavenging enzyme, are frequently observed, while other antioxidative enzymes are induced [3, 14-16]. Recently, we found that a BA2H inhibitor, 
which reduces SA accumulation, resulted in the restoration of CAT activity and alleviated oxidative injury in rice seedlings under salt stress [17]. Therefore, we hypothesized that the reduction of CAT activity by accumulated SA and the accompanying generation of $\mathrm{H}_{2} \mathrm{O}_{2}$ might be involved in the oxidative injury caused by salinity in rice seedlings.

To further clarify the action of SA in plant tissue under salt stress, we investigated the effects of foliar-applied SA on the salt sensitivity, $\mathrm{H}_{2} \mathrm{O}_{2}$ generation, and antioxidative enzyme activities. To this end, barnyardgrass (Echinochloa crus-galli var. formosensis Ohwi), a gramineous weed which grows in paddy fields and therefore competes with rice for growth, was selected as a plant material because it is known to have lower SA contents and a higher salt tolerance than rice [18, 19]. The changes in the free and conjugated SA contents of this plant under salt treatment were also examined.

\section{Materials and Methods}

\subsection{Plant Materials and Treatments}

Seeds of barnyardgrass (Echinochloa crus-galli Beauv. var. formsensis Ohwi) were germinated in an incubator at $30^{\circ} \mathrm{C}$ for $48 \mathrm{~h}$ in the dark and then transferred to a growth chamber under a 12 -h photoperiod $\left(25 / 20^{\circ} \mathrm{C}\right.$; day/night, $\left.200 \mu \mathrm{mol} \mathrm{m} \mathrm{m}^{-2} \mathrm{~s}^{-1}\right)$ and $60 \%$ relative humidity. The seedlings were grown in a modified Kasugai's nutrient solution [20] for 3 weeks until the 3rd leaf stage. To impose salt stress, the seedlings were transferred to a nutrient solution containing 0,80 , or $120 \mathrm{mM} \mathrm{NaCl}$ for 3 days. For the SA treatment and salt stress, the seedlings were pre-treated by spraying $0.5 \mathrm{mM} \mathrm{SA}$ (Sigma, St. Louis, USA) solution ( $\mathrm{pH}$ 6.8) one day before the salt stress with an atomizer onto the leaf blades until it ran off. Distilled water $(\mathrm{pH} \mathrm{6.8)} \mathrm{was} \mathrm{applied} \mathrm{to} \mathrm{the}$ leaves of control plants. The seedlings were then transferred to the nutrient solution 
containing $120 \mathrm{mM} \mathrm{NaCl}$ for 3 days.

The 3rd leaves (the youngest fully expanded leaves) of the seedlings were harvested, frozen in liquid nitrogen, and then stored at $-80^{\circ} \mathrm{C}$ for further analysis. The salt-stressed responses were clearer in the 3rd leaves rather than the growing 4th leaves (data not shown).

\subsection{Chlorophyll Fluorescence Measurement}

Chlorophyll fluorescence was measured on the 3rd leaf blades of the above intact seedlings using a chlorophyll fluorometer (MINI-PAM, WALZ, Effeltrich, Germany) with light-emitting diodes at a peak wavelength of $655 \mathrm{~nm}$ and an $18,000 \mu \mathrm{mol} \mathrm{m}^{-2} \mathrm{~s}^{-1}$ saturation pulse. The efficiency of photosystem II photochemistry $\left(\Phi_{\mathrm{PSII}}\right)$ was calculated according to Gentry et al. [21].

\subsection{Antioxidative Enzyme Extraction and Activity Assays}

Leaf samples $(0.5 \mathrm{~g}$ fresh weight; FW) were ground into a fine powder in liquid nitrogen with a chilled mortar and pestle and transferred into a potassium phosphate buffer (25mM, pH7.8) containing $0.4 \mathrm{mM}$ ethylenediamine tetra-acetic acid (EDTA-4H), $1 \mathrm{mM}$ ascorbate and 2\% (w/v) polyvinylpolypyrrolidone. The mixture was homogenized and then centrifuged at $15,000 \times g$ for $20 \mathrm{~min}$ at $4{ }^{\circ} \mathrm{C}$. The supernatant, filtered through 1 layer of Myracloth ${ }^{\circledR}$ (Calbiochem, San Diego, USA), was used as the crude enzyme solution. The filtrate was then used as an enzyme extract for CAT (EC 1.11.1.6), ascorbate peroxidase (APX; EC 1.11.1.11), and glutathione reductase (GR; EC 1.6.4.2) assays. For the assay of superoxide dismutase (SOD; EC 1.15.1.1), the enzyme extract was dialyzed against Seamless Cellulose Tubing ${ }^{\circledR}$ (Wako, Osaka, Japan) overnight with $10 \mathrm{mM}$ potassium phosphate buffer $(\mathrm{pH} 7.8)$ at $4{ }^{\circ} \mathrm{C}$. CAT activity was determined by 
the method of Aebi [22]. The activity was assayed in a $1 \mathrm{~mL}$ reaction mixture containing $0.95 \mathrm{~mL}$ of $50 \mathrm{mM}$ potassium phosphate buffer $\left(\mathrm{pH} 7.0\right.$, containing $10 \mathrm{mM} \mathrm{H}_{2} \mathrm{O}_{2}$ ) and $0.05 \mathrm{~mL}$ of enzyme extract. Subsequent decomposition of $\mathrm{H}_{2} \mathrm{O}_{2}$ was observed at 240 $\mathrm{nm}$.

APX activity was determined by the method of Nakano and Asada [23]. The activity was assayed in a $1 \mathrm{~mL}$ reaction mixture containing $0.25 \mathrm{~mL}$ of $100 \mathrm{mM}$ potassium phosphate buffer ( $\mathrm{pH} 7.0$ ), $0.25 \mathrm{~mL}$ of $1 \mathrm{mM}$ ascorbic acid, $0.25 \mathrm{~mL}$ of $0.4 \mathrm{mM}$ EDTA-4H, $0.01 \mathrm{~mL}$ of $10 \mathrm{mM} \mathrm{H} \mathrm{O}_{2}, 0.19 \mathrm{mLl}$ distilled water, and $0.05 \mathrm{~mL}$ of enzyme extract. A subsequent decrease in ascorbic acid was observed at $290 \mathrm{~nm}$.

GR activity was determined by the method of Halliwel and Foyer [24]. The activity was assayed in a $1 \mathrm{~mL}$ reaction mixture containing $0.25 \mathrm{~mL}$ of $100 \mathrm{mM}$ potassium phosphate buffer ( $\mathrm{pH} 7.8), 0.05 \mathrm{~mL}$ of $10 \mathrm{mM}$ oxidized glutathione, $0.12 \mathrm{~mL}$ of $1 \mathrm{mM}$ NADPH, $0.48 \mathrm{~mL}$ of distilled water, and $0.1 \mathrm{~mL}$ of enzyme extract. A resultant decrease in NADPH was observed at $340 \mathrm{~nm}$.

SOD activity was determined by the method of Asada [25]. SOD activity was assayed in a $1 \mathrm{~mL}$ reaction mixture containing $0.1 \mathrm{~mL} 500 \mathrm{mM}$ potassium phosphate buffer $(\mathrm{pH}$ 7.8, containing $0.1 \mathrm{mM}$ EDTA-4H), $0.1 \mathrm{~mL}$ of $1 \mathrm{mM}$ cytochome $c$ from horse heart, 0.1 $\mathrm{mL}$ of $1 \mathrm{mM}$ xanthine dissolved in $10 \mathrm{mM} \mathrm{NaOH}, 0.02 \mathrm{~mL}$ of xanthine oxidase, 0.66 $\mathrm{mL}$ of distilled water, and $0.02 \mathrm{~mL}$ of dialyzed enzyme extract. The reduction rate of cytochrome $c$ was measured in terms of the initial rate of increase in absorbance at 550 nm.

The protein concentration of the crude enzyme extracted from E. crus-galli leaves was measured according to Bradford [26].

\subsection{Free and Conjugated Salicylic Acid Measurement}


The extraction and determination of free salicylic acid were conducted according to the method of Malamy et al. [27]. Leaf samples $(0.3 \mathrm{~g} \mathrm{FW})$ were ground with $7 \mathrm{~mL}$ of $90 \%$ methanol and centrifuged at $7,000 \times g$ for $15 \mathrm{~min}$. The pellets were re-extracted with $2 \mathrm{~mL}$ of $90 \%$ methanol and centrifuged again as mentioned above. The supernatants from both centrifuge steps were evaporated in vacuo at $35^{\circ} \mathrm{C}$ to remove the methanol. Distilled water $(5 \mathrm{~mL})$ was added to resuspend the extracts at $80^{\circ} \mathrm{C}$ in a water bath for 2 min. For free SA extraction, half of the extract was added to an equal volume of $0.2 \mathrm{M}$ sodium acetate ( $\mathrm{pH} 4.5$ ), and $\mathrm{pH}$ was adjusted to 1.5 to 2.0 using $\mathrm{HCl}$. To quantify glucose-conjugated SA, the remaining half of the extract was incubated overnight at $37^{\circ} \mathrm{C}$ with an equal volume of $0.2 \mathrm{M}$ sodium acetate $(\mathrm{pH} 4.5)$ containing 10 U $\beta$-glucosidase (EC 3.2.1.21; from almond; Oriental Yeast, Tokyo, Japan.). After hydrolysis, the samples were acidified to $\mathrm{pH} 1.5$ to 2.0 using $\mathrm{HCl}$. Untreated and glucosidase-treated fractions were extracted using two volumes of ethyl acetate: cyclopentane: 2-propanol (50:50:1; v/v/v), and evaporated in vacuo at $35^{\circ} \mathrm{C}$ to be fully dried. The residues were dissolved in $23 \%(\mathrm{v} / \mathrm{v})$ methanol $/ 20 \mathrm{mM}$ sodium acetate $(\mathrm{pH}$ 5.0), and were subjected to HPLC (LC-10AS; Shimadzu, Kyoto, Japan) using a column ( $\mu$ Bondasphere $5 \mu \mathrm{C} 18-100 \mathrm{~A}, 3.9 \times 150 \mathrm{~mm}$; Waters, Milford, USA) at $35^{\circ} \mathrm{C}$ and a 1.0 $\mathrm{mL} / \mathrm{min}$ flow rate of solvent $(23 \%(\mathrm{v} / \mathrm{v})$ methanol/20 mM sodium acetate buffer; $\mathrm{pH}$ 5.0). Free and conjugated SAs were analyzed by using a spectrofluorescence detector (RF-10AXL; Shimadzu, Kyoto, Japan) at the excitation wavelength of $313 \mathrm{~nm}$ and an emission wavelength of $405 \mathrm{~nm}$.

\section{$2.5 \mathrm{H}_{2} \mathrm{O}_{2}$ Content Measurement}

Hydrogen peroxide levels were determined according to Velikova et al. [28]. Leaf tissues $(0.5 \mathrm{~g} \mathrm{FW})$ were homogenized in an ice bath with $5 \mathrm{ml} 0.1 \%(\mathrm{w} / \mathrm{v})$ TCA. The 
homogenate was centrifuged at $12,000 \times g$ for $15 \mathrm{~min}$, and $0.5 \mathrm{ml}$ of the supernatant was added to $0.5 \mathrm{ml} 10 \mathrm{mM}$ potassium phosphate buffer $(\mathrm{pH} \mathrm{7.0)}$ and $1 \mathrm{ml} 1 \mathrm{M} \mathrm{KI}$. The absorbancy of the supernatant was read at $390 \mathrm{~nm}$. The content of $\mathrm{H}_{2} \mathrm{O}_{2}$ was given on a standard curve.

\subsection{Statistics}

All the data presented here were based on two independent experiments with three replications. In each experiment three different pots were used for the same treatment. SPSS (Ver. 11.0J) software was used for the statistical analysis. To assess the statistical significance of the treatment differences, a one-way analysis of variance (ANOVA) followed by Tukey's multiple comparison test or $t$-test (with $P$ set at 0.05 ) was employed.

\section{Results}

3.1 Effects of NaCl Treatment on the Shoot Growth, Chlorophyll Fluorescence, and Salicylic Acid Content in E. crus-galli

E. crus-galli seedlings showed no serious damage even at $120 \mathrm{mM} \mathrm{NaCl}$ (Fig. 1A) compared with rice seedlings in which the growth was inhibited depending on the $\mathrm{NaCl}$ concentration, and the first and second leaves exhibited wilting at $120 \mathrm{mM} \mathrm{NaCl}$ (Fig. 1 B). The shoot growth of E. crus-galli, especially the forth leaf, was repressed by 80 and $120 \mathrm{mM} \mathrm{NaCl}$ treatment (Fig. 1A). However, the fresh weight of the whole shoot decreased only to 88 and $79 \%$ of the control seedlings at three days after the 80 and 120 $\mathrm{mM} \mathrm{NaCl}$ treatments, respectively (Fig. 2A). Similarly, the chlorophyll fluorescence ( $\left.\Phi_{\text {PSII }}\right)$ of the leaf blade was not significantly affected by the $\mathrm{NaCl}$ treatment both at 80 $\mathrm{mM}$ and at $120 \mathrm{mM}$ over three days (Fig. 2B), although prolonged treatment (six days) 
with $120 \mathrm{mM} \mathrm{NaCl}$ resulted in a $27 \%$ decrease in $\Phi_{\text {PSII }}$ value (data not shown).

In E. crus-galli seedlings exposed to 80 or $120 \mathrm{mM} \mathrm{NaCl}$, neither free SA nor conjugated SA showed any significant increase over three days (Figs. 2C and D).

\subsection{Effects of SA Pre-Treatment on Shoot Growth, Chlorophyll Fluorescence, and $\mathrm{H}_{2} \mathrm{O}_{2}$}

Content in E. crus-galli under Salt Stress

In the seedlings treated with $0.5 \mathrm{mM}$ SA by foliar spraying, the free and conjugated SA contents in the 3rd leaves increased up to $160 \%$ and $165 \%$, respectively, of those of the control seedlings after one day (Table I).

In the absence of salinity, such foliar treatment with exogenous SA did not affect either the shoot growth or $\Phi_{\mathrm{PSII}}$ in E. crus-galli seedlings (Figs. 3A and B). However, in the presence of salinity, the growth inhibitory effect of salt was reinforced with SA pre-treatment; the increase of the shoot fresh weight over three days was completely blocked when E. crus-galli seedlings were treated with $120 \mathrm{mM} \mathrm{NaCl}$ after foliar treatment with SA (Fig. 3A). Similarly, SA pre-treatment caused a remarkable decrease in $\Phi_{\mathrm{PSII}}$ in E. crus-galli seedlings three days after the $\mathrm{NaCl}$ treatment, while the $\Phi_{\mathrm{PSII}}$ value hardly changed in the seedlings treated with $\mathrm{NaCl}$ alone (Fig. 3B). The $\mathrm{H}_{2} \mathrm{O}_{2}$ content of the leaves did not statistically change as a result of treatment with either 0.5 mM SA or $120 \mathrm{mM} \mathrm{NaCl}$ alone (Fig. 4). However, a significant increase in the $\mathrm{H}_{2} \mathrm{O}_{2}$ content of $46 \%$ above the level in the control seedlings could be observed in the seedlings treated with $\mathrm{NaCl}$ after foliar treatment with SA (Fig. 4).

3.3 Effects of SA Pre-Treatment on the Activities of Antioxidative Enzymes in E. crus-galli under Salt Stress

CAT activity was significantly induced after one day of salt treatment in the leaves of 
E. crus-galli seedlings (Fig. 5A). Such an induction of CAT activity was strongly repressed with SA pre-treatment: The CAT activity was 30\% lower than that of the seedlings treated with $\mathrm{NaCl}$ alone and decreased to the level of the control seedlings after three days.

APX activity was also induced by the salt treatment, while GR activity was slightly inhibited (Figs. 5B and C). SA pre-treatment did not affect either the APX or GR activities of the seedlings exposed to salinity.

SOD activity was significantly induced one day after the $\mathrm{NaCl}$ treatment, although the SOD activity transiently increased only with SA pre-treatment prior to $\mathrm{NaCl}$ treatment (Fig. 5D). In contrast with the CAT activity, however, the increase of the SOD activity under salinity was further enhanced with SA pre-treatment: Foliar application of SA brought about an over five-fold increase in the SOD activity after three days (Fig. 5D).

\section{Discussion}

Salinity caused growth inhibition and decreased efficiency in photosynthetic energy conversion $\left(\Phi_{\mathrm{PSII}}\right)$ in E. crus-galli seedlings (Figs. 2A and B). However, the growth inhibition and damage symptoms in E. crus-galli were not as severe as those in rice seedlings (Fig. 1). The preliminary experiment using rice seedlings showed that 120 $\mathrm{mM}$ of $\mathrm{NaCl}$ caused a striking decrease in the leaf blade $\Phi_{\mathrm{PSII}}$ value (a $37 \%$ and $64 \%$ decrease after three and six days, respectively). The present results supported the results of an earlier report showing that the gramineous weed E. crus-galli is more tolerant of salt stress than rice [19]. The decrease in $\Phi_{\mathrm{PSII}}$ accounts for the occurrence of the disorder in photosynthetic electron transport, which leads to the generation of ROS such as $\mathrm{O}_{2}{ }^{-}$and $\mathrm{H}_{2} \mathrm{O}_{2}$ [29]. Thus, it appeared that the difference in salt tolerance between 
rice and E. crus-galli might be associated with the difference in their ability to scavenge cytotoxic ROS.

CAT is known as a major $\mathrm{H}_{2} \mathrm{O}_{2}$ scavenging enzyme in higher plants and is generally induced by various oxidative stresses in stress-tolerant plants [30, 31]. It has been reported that the accumulation of $\mathrm{H}_{2} \mathrm{O}_{2}$ due to a decrease in CAT activity or CAT deficiency is involved in susceptibility to environmental stresses [32, 33]. In $E$. crus-galli seedlings, the CAT activity increased immediately after $\mathrm{NaCl}$ treatment (Fig. 5A), while CAT activity in rice seedlings decreased under salt stress [3, 14], indicating an apparent difference between those plants in terms of their $\mathrm{H}_{2} \mathrm{O}_{2}$ scavenging ability.

The free and conjugated SA contents in the leaves of E. crus-galli were 0.5 and 3.4 $\mu \mathrm{g} \mathrm{g}^{-1} \mathrm{FW}$, respectively, which were $1 / 10$ and $1 / 20$ lower than those in rice leaves [11]. Our previous study [11] showed that SA biosynthetic enzyme (BA2H) in rice seedlings was induced immediately after salt stress and was accompanied by a remarkable increase in free SA (a two-fold increase one day after $80 \mathrm{mM} \mathrm{NaCl}$ treatment). In $E$. crus-galli seedlings, however, neither free nor conjugated SA contents showed any increase resulting from the treatment with $80 \mathrm{mM}$ or $120 \mathrm{mM} \mathrm{NaCl}$ (Figs. $2 \mathrm{C}$ and D). The two pathways of SA biosynthesis have been so far revealed: One is the pathway via benzoic acid from phenylalanine and the other via isochorismate [34]. Ogawa et al. [35] showed that transcription levels of phenylalanine ammonia-lyase genes were increased to a greater extent in the $\mathrm{O}_{3}$-sensitive tobacco $(\mathrm{Bel} \mathrm{W} 3)$ than in the $\mathrm{O}_{3}$-tolerant tobacco (Bel B) and Pasqualini et al. [36] found that Bel W3 accumulated higher levels of SA than did Bel $\mathrm{B}$ after $\mathrm{O}_{3}$ exposure. In contrast, SA was reported to be synthesized by isochorismate synthase in Arabidopsis after exposure of $\mathrm{O}_{3}$ [35]. Although the synthetic route or metabolic pathway of SA in E. crus-galli is unknown at present, our results suggested that the expression of the genes involved in SA synthesis was not induced 
with salt stress in E. crus-galli.

Mohase and van der Westhuizen [37] found that the pattern and extent of CAT inhibition largely coincided with those of SA accumulation. It was reported that specific binding of SA to plant CAT resulted in the reduction of CAT activity and in elevated $\mathrm{H}_{2} \mathrm{O}_{2}[13,38]$. Kim et al. [39] showed a reduction of CatA and CatC expression at the mRNA level in rice seedlings subjected to salt stress. It was also reported that CatC gene was down regulated in rice leaves treated with SA [40]. These data, together with our finding that, unlike the salt-sensitive rice seedlings, salt-tolerant E. crus-galli seedlings induced CAT activity but not SA synthesis under high salinity, strongly suggest that the accumulation of SA depresses the stress tolerance of plants through the inhibition of CAT.

To ascertain whether the elevation of the tissue SA level results in a reduction of CAT activity, an increase in $\mathrm{H}_{2} \mathrm{O}_{2}$ and an alteration of stress tolerance, the effects of exogenous SA on E. crus-galli seedlings under high salinity were examined. Foliar application of SA significantly increased not only free SA but also conjugated SA in the leaves (Table I). Absorbed SA itself affected neither the shoot growth nor the $\Phi_{\text {PSII }}$ value of E. crus-galli (Fig. 3). However, $120 \mathrm{mM} \mathrm{NaCl}$ treatment after foliar spraying of SA enhanced both salt stress-induced growth inhibition and the decrease in the $\Phi_{\text {PSII }}$ value. Preliminary experiments showed that pre-treatments with 0.01 to $1 \mathrm{mM}$ SA reinforced the growth inhibitory effect of salt stress, and the damage was more severe with higher SA concentrations. Furthermore, such exogenous SA treatment resulted in the striking suppression of CAT activity (Fig. 5A) and significant increases in $\mathrm{H}_{2} \mathrm{O}_{2}$ content in the seedlings under high salinity (Fig. 4). The increase rate of $\mathrm{H}_{2} \mathrm{O}_{2}$ was much higher than that in rice seedlings exposed to the same salt concentration (data not shown).

A remarkable elevation of SOD activity under SA pre-treatment was also observed in 
the present experiment (Fig. 5D). SA and ROS have been proposed to be on a positive feedback loop [41]. Kawano et al. [42] reported that the addition of SA to tobacco suspension culture induces $\mathrm{O}_{2} \cdot{ }^{-}$generation through the extracellular peroxidase-catalyzed oxidation of SA. SOD is an enzyme that catalyzes a dismutation reaction which converts $\mathrm{O}_{2}{ }^{-}$- to $\mathrm{H}_{2} \mathrm{O}_{2}$ [25]. Therefore, the promotion of SOD activity by exogenous SA is also considered to be involved in the observed elevation of leaf $\mathrm{H}_{2} \mathrm{O}_{2}$ under salt stress.

The present study demonstrated that the enlargement of the cellular SA pool potentiates oxidative injury under salt stress, possibly due to the elevation of $\mathrm{H}_{2} \mathrm{O}_{2}$ caused by the decreased CAT and increased SOD activities. The repression of free SA formation under high salinity observed in E. crus-galli (Fig. 2C) could be one of the strategies of this highly adaptive weed for coping with various environmental stresses. It was reported that SA-deficient Arabidopsis thaliana expressing SA hydroxylase (NahG), which catalyzes SA breakdown, was better able to resist the oxidative damage generated by salt and osmotic stress than the wild-type plants [43]. Recently, we also observed that the suppression of SA accumulation by $\mathrm{BA} 2 \mathrm{H}$ inhibitor is effective in alleviating salt stress injury in rice seedlings $[11,17]$. The genes related to the metabolic regulation of SA might be promising targets in rice breeding for improving the stress tolerance of this important gramineous crop. 


\section{References}

[1] J.P. Metraux, H. Signer, J. Ryals, E. Ward, M. Wyss-Benz, J. Gaudin, K. Raschdorf, E. Schmid, W. Blum, B. Inverardi, Increase in salicylic acid at the onset of systemic acquired resistance in cucumber., Science 250 (1990) 1004-1006.

[2] N. Yalpani, A.J. Enyedi, J. Leon, I. Raskin, Ultraviolet light and ozone stimulate accumulation of salicylic acid, pathogenesis-related proteins and virus resistance in tobacco., Planta 193 (1994) 372-376.

[3] I.S. Shim, Y. Momose, A. Yamamoto, D.W. Kim, K. Usui, Inhibition of catalase activity by oxidative stress and its relationship to salicylic acid accumulation in plants., Plant Growth Regul. 39 (2003) 285-292.

[4] I.M. Scott, S.M. Clarke, J.E. Wood, L.A.J. Mur, Salicylate accumulation inhibits growth at chilling temperature in Arabidopsis, Plant Physiol. 135 (2004) 1040-1049.

[5] T. Janda, G. Szalai, I. Tari, E. Paldi, Hydroponic treatment with salicylic acid decreases the effects of chilling injury in maize (Zea mays L.) plants, Planta 208 (1999) 175-180.

[6] B. Singh, Usha, K., Salicylic acid induced physiological and biochemical changes in wheat seedlings under water stress., Plant Growth Regul. 39 (2003) 137-141.

[7] M. Arfan, H.R. Athar, M. Ashraf, Does exogenous application of salicylic acid through the rooting medium modulate growth and photosynthetic capacity in two differently adapted spring wheat cultivars under salt stress?, J. Plant Physiol. 164 (2007) 685-694.

[8] A. Gunes, A. Inal, M. Alpaslan, F. Eraslan, E.G. Bagci, N. Cicek, Salicylic acid induced changes on some physiological parameters symptomatic for oxidative stress and mineral nutrition in maize (Zea mays L.) grown under salinity., J. Plant Physiol. 164 
(2007) 728-736.

[9] M.V. Rao, K.R. Davis, Ozone-induced cell death occurs via two distinct mechanisms in Arabidopsis: the role of salicylic acid., Plant J. 17 (1999) 603-614.

[10] M. Nemeth, T. Janda, E. Horvath, E. Paldi, G. Szalai, Exogenous salicylic acid increases polyamine content but may decrease drought tolerance in maize, Plant Sci. $162(2002) 569-574$.

[11] H. Sawada, I.-S. Shim, K. Usui, Induction of benzoic acid 2-hydroxylase and salicylic acid biosynthesis--Modulation by salt stress in rice seedlings, Plant Science 171 (2006) 263-270.

[12] J. Durner, D.F. Klessig, Inhibiton of ascorbate peroxidase by salicylic acid and 2,6-dichloroisonicotinic acid, two inducers of plant defence responses., Proc. Natl. Acad. Sci. USA 92 (1995) 11312-11316.

[13] M. Ruffer, B. Steipe, M.H. Zenk, Evidence against specific binding of salicylic acid to plant catalase, FEBS Lett. 377 (1995) 175-180.

[14] I.S. Shim, Naruse, Y., Kim, Y.H., Kobayasi, K., Usui, K., Scavenging Activity of NaCl-induced Activated Oxygen in Two Rice (Oryza sativa L.) Cultivars Differing in Salt Tolerance., Jpn.J.Trop.Agr. 43 (1999) 32-41.

[15] D.H. Lee, Y.S. Kim, C.B. Lee, The inductive responses of antioxidant enzymes by salt stress in the rice (Oryza sativa L.). J. Plant Physiol. 158 (2001) 737-745.

[16] K. Yamane, M.S. Rahman, M. Kawasaki, M. Taniguchi, H. Miyake, Pretreatment with a low concentration of methyl viologen decreases the effects of salt stress on chloroplast ultrastructure in rice leaves (Oryza sativa L.). Plant Prod. Sci. 7 (2004) 435-441.

[17] H. Sawada, D.-W. Kim, K. Kobayashi, I.-S. Shim, Inabenfide-induced alleviation of salt stress in rice as linked to changes in salicylic acid content and catalase 
activity, J. Crop Sci. Biotech. 10 (2007) 41-46.

[18] I. Raskin, H. Skubatz, W. Tang, B.J.D. Meeuse, Salicylic acid levels in thermogenic and non-thermogenic plants., Annal. Bot. 66 (1990) 369-373.

[19] A. Yamamoto, I.S. Shim, S. Fujihara, T. Yoneyama, K. Usui, Physiochemical factors affecting the salt tolerance of Echinochloa crus-galli Beauv. var. formosensis Ohwi, Weed Biology and Management 3 (2003) 98-104.

[20] S. Kasugai, Studies on the hydroponic cultures., J. Sci. Soil Manure (in Japanese) 13 (1939) 669-822.

[21] B. Gentry, J.-M. Briantais, N.R. Baker, The relationship between quantum yield of photosynthetic electron transport and quenching of chlorophyll fluorescence. Biochim Biophys Acta 990 (1989) 87-92.

[22] H. Aebi, Catalase, in: H.U. Bergmeyer (Ed.), Methods of Enzymatic Analysis, 2nd Engl. Ed., vol. 2, Verlag Chemie, Deerfield Beach, FL, 1974, pp. 673-684.

[23] Y. Nakano, K. Asada, Hydrogen peroxide is scavenged by ascorbate-specific peroxidase in spinach chloroplasts., Plant Cell Physiol. 22 (1981) 867-880.

[24] B. Halliwell, C.H. Foyer, Properties and physiological function of a glutathione reductase purified from spinach leaves by affinity chromatography, Planta 139 (1978) 9-17.

[25] K. Asada, Superoxide dismutase, Protein, Nucleic Acid and Enzyme (Supplement), Kyoritsu Shuppan, Tokyo, Japan, 1976, pp. 373-377.

[26] M.M. Bradford, A rapid and sensitive method for the quantitation of microgram quantities of protein utilizing the principle of protein-dye binding, Analytical Biochemistry 72 (1976) 248-254.

[27] J. Malamy, J. Hennig, D.F. Klessig, Temperature-dependent induction of salicylic acid and its conjugates during the resistance response to tobacco mosaic virus 
infection, Plant Cell 4 (1992) 359-366.

[28] V. Velikova, I. Yordanov, A. Edreva, Oxidative stress and some antioxidant systems in acid rain-treated bean plants. Protextive role of exogenous polyamines, Plant Sci. 151 (2000) 59-66.

[29] G. Noctor, S. Veljovic-Jovanovic, S. Driscoll, L. Novitskaya, C.H. Foyer, Drought and oxidative load in the leaves of C3 plants: a predominant role for photorespiration?, Annal. Bot. 89 (2002) 841-850.

[30] A. Shalata, M. Tal, The effect of salt stress on lipid peroxidation and antioxidants in the leaf of the cultivated tomato and its wild salt-tolerant relative Lycopersicon pennellii, Physiol. Pranta. 104 (1998) 169-174.

[31] A.L.S. Lima, F.M. DaMatta, H.A. Pinheiro, M.R. Totola, M.E. Loureiro, Photochemical responses and oxidative stress in two clones of Coffea canephora under water deficit conditions, Environmental and Experimental Botany 47 (2002) 239-247.

[32] R.G. Omran, Peroxide levels and the activities of catalase, peroxidase, and indoleacetic acid oxidase during and after chilling cucumber seedlings, Plant Physiol. 65 (1980) 407-408.

[33] H. Willekens, S. Chamnogpol, M. Davey, M. Schrandner, C. Langabartels, M.V. Montagu, D. Inze, W. Van Camp, Catalase is a sink for $\mathrm{H}_{2} \mathrm{O}_{2}$ and is indispensable for stress defense in $\mathrm{C}_{3}$ plants, The EMBO J. 16 (1997) 4806-4816.

[34] T. Kawano, T. Furuichi, S. Muto, Controlled salicylic acid levels and corresponding signaling mechanisms in plants, Plant Biotech. 21 (2004) 319-335.

[35] D. Ogawa, Nakajima, N., Sano, T., Tamaoki, M., Aono, M., Kubo, A., Kanna, M., Ioki, M., Kamada, H. and Saji, H., Salicylic Acid Accumulation Under $\mathrm{O}_{3}$ exposure is Regulated by Ethylene in Tobacco Plants, Plant Cell Physiol. 46 (2005) 1062-1072.

[36] S. Pasqualini, G.D. Torre, F. Ferranti, L. Ederli, C. Piccioni, L. Reale, M. 
Antonielli, Salicylic acid modulates ozone-induced hypersensitive cell death in tobacco plants., Physiol. Pranta. 115 (2002) 204-212.

[37] L. Mohase, A.J. van der Westhuizen, Salicylic acid is involved in resistance response in the Russian wheat aphid-wheat interaction, J. Plant Physiol. 159 (2002) $585-590$.

[38] Z. Chen, H. Silva, D.F. Klessig, Active oxygen species in the induction of plant systemic acquired resistance by salicylic acid, Science 262 (1993) 1883-1886.

[39] D.W. Kim, J. Shibato, G.K. Agrawal, S. Fujihara, H. Iwahashi, H. Kim du, S. Shim Ie, R. Rakwal, Gene transcription in the leaves of rice undergoing salt-induced morphological changes (Oryza sativa L.), Mol Cells 24 (2007) 45-59.

[40] G.K. Agrawal, R. Rakwal, N. Jwa, Stress signaling molecules involved in defense and protein phosphatase $2 \mathrm{~A}$ inhibitors modulate OsCATC expression in rice (Oryza sativa) seedlings, J.Plant Physiol. 158 (2001) 1349-1355.

[41] J. Draper, Salicylate, superoxide synthesis and cell suicide in plant defence, TREND Plant Sci. 2 (1997) 162-165.

[42] T. Kawano, N. Sahashi, K. Takahashi, N. Uozumi, S. Muto, Salicylic acid induces extracellular superoxide generation followed by an increase in cytosolic calcium ion in tobacco suspension culture: The earliest events in salicylic acid signal transduction, Plant Cell Physiol. 39 (1998) 721-730.

[43] O. Borsani, V. Victoriano, M.A. Botella, Evidence for a role of salicylic acid in the oxidative damage generated by $\mathrm{NaCl}$ and osmotic stress in Arabidopsis seedlings, Plant Physiol. 126 (2001) 1024-1030. 


\section{FIGURE CAPTIONS AND LEGENDS}

Fig. 1. Echinochloa crus-galli (A) and rice (B) seedlings subjected to $\mathrm{NaCl}$ treatment for three days. E. crus-galli and rice seedlings were grown hydroponically for three weeks.

Fig. 2. Effects of $\mathrm{NaCl}$ treatment on the fresh weight of shoots and the chlorophyll fluorescence and SA content in the 3rd leaves of Echinochloa crus-galli seedlings. (A) Fresh weight. (B) Chlorophyll fluorescence ( $\left.\Phi_{\text {PSII }}\right)$. (C) Free SA content. (D) Conjugated SA content. Asterisks indicate significant differences at $P<0.05$ compared with their controls according to Tukey's multiple comparison test. Bars indicate \pm S.E. $(n=3)$.

Fig. 3. Effects of SA pre-treatment on the fresh weight of shoots and the chlorophyll fluorescence $\left(\Phi_{\mathrm{PSII}}\right)$ in Echinochroa crus-galli seedlings. SA solution $(0.5 \mathrm{mM}, \mathrm{pH} 6.8)$ was sprayed on the seedlings one day before $120 \mathrm{mM} \mathrm{NaCl}$ treatment. (A) Fresh weight.

(B) Chlorophyll fluorescence $\left(\Phi_{\mathrm{PSII}}\right)$. Asterisks indicate significant differences at $P<0.05$ between the $\mathrm{NaCl}$ treatment and the $\mathrm{SA}+\mathrm{NaCl}$ treatment according to the $t$-test. Bars indicate \pm S.E. $(n=3)$.

Fig. 4. Effect of SA pre-treatment on $\mathrm{H}_{2} \mathrm{O}_{2}$ content in the 3rd leaves of Echinochloa crus-galli seedlings with or without $\mathrm{NaCl}$ treatment. $120 \mathrm{mM} \mathrm{NaCl}$ was treated for three days after foliar application of distilled water (DW) or $0.5 \mathrm{mM} \mathrm{SA}$. Asterisk indicates significant difference at $P<0.05$ compared with their controls according to the $t$-test. Bars indicate \pm S.E. $(n=3)$. 
Fig. 5. Effects of SA pre-treatment on $\mathrm{NaCl}$-induced change in the activities of antioxidative enzymes in Echinochroa crus-galli seedlings. SA solution $(0.5 \mathrm{mM}, \mathrm{pH}$ 6.8) was sprayed on the seedlings one day before $120 \mathrm{mM} \mathrm{NaCl}$ treatment. (A) Catalase (CAT). (B) Ascorbate peroxidase (APX). (C) Glutathione reductase (GR). (D) Superoxide dismutase (SOD). Asterisks indicate significant differences at $P<0.05$ between the $\mathrm{NaCl}$ treatment and the $\mathrm{SA}+\mathrm{NaCl}$ treatment according to the $t$-test. Bars indicate \pm S.E. $(\mathrm{n}=3)$. 
Table 1. SA content in the 3rd leaves of Echinochloa crus-galli seedlings one day after foliar application of SA.

\begin{tabular}{llll}
\hline & Control & SA & \\
\hline Free SA $\left(\mu \mathrm{g} \mathrm{g}^{-1} \mathrm{FW}\right)$ & $0.72 \pm 0.09$ & $1.15 \pm 0.12(160 \%)^{*}$ \\
Conjugated SA $\left(\mu \mathrm{g} \mathrm{g}^{-1} \mathrm{FW}\right)$ & $2.92 \pm 0.04$ & $4.81 \pm 0.39(165 \%)^{*}$ \\
\hline
\end{tabular}

Values are mean \pm S.E. $(n=3)$. Values in parentheses represent a percentage of the control value. SA solution $(0.5 \mathrm{mM}$, pH6.8) was sprayed on the seedlings with an atomizer.

* Significant at the $P<0.05$ level compared to control. 

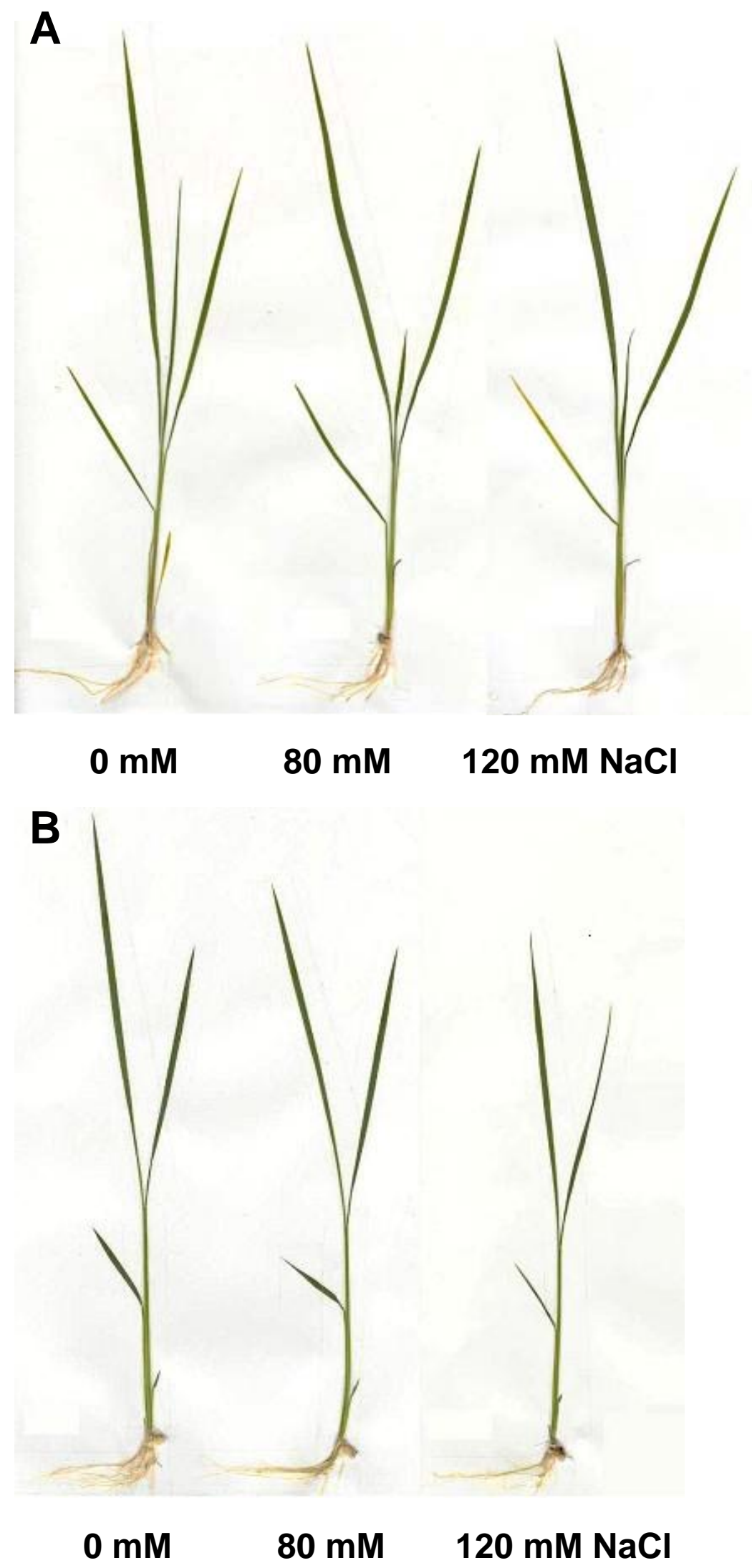

Fig. 1 

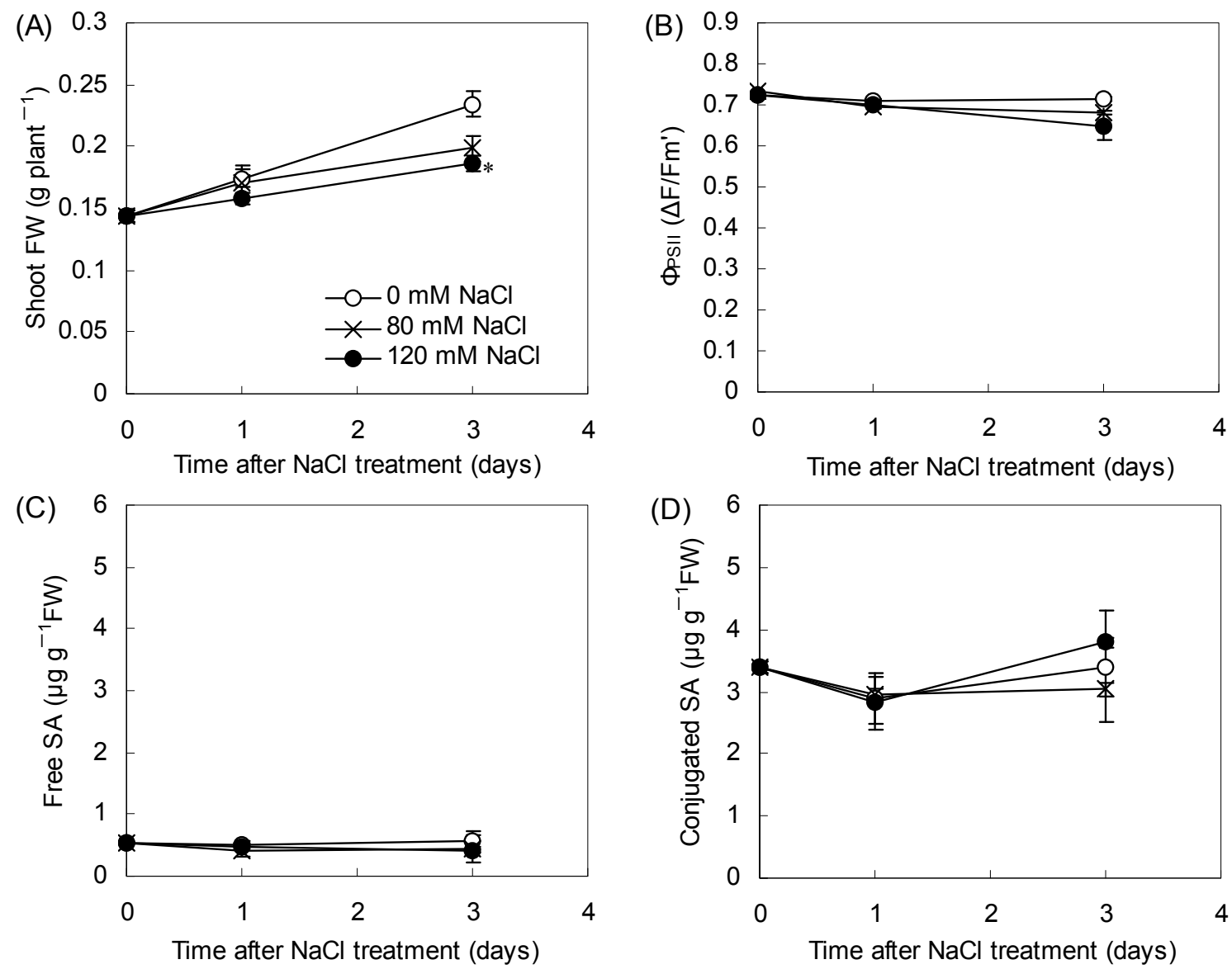

Fig. 2 

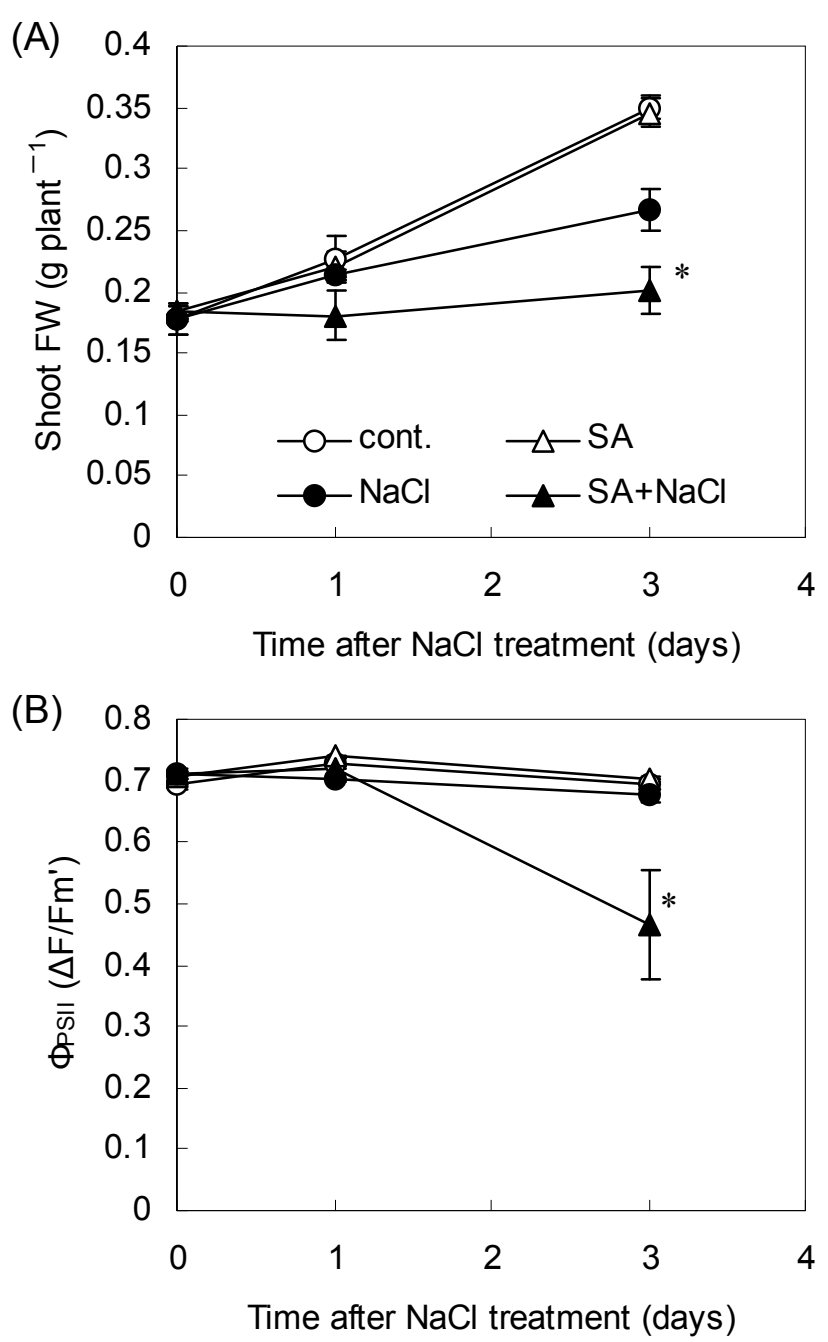

Fig. 3 


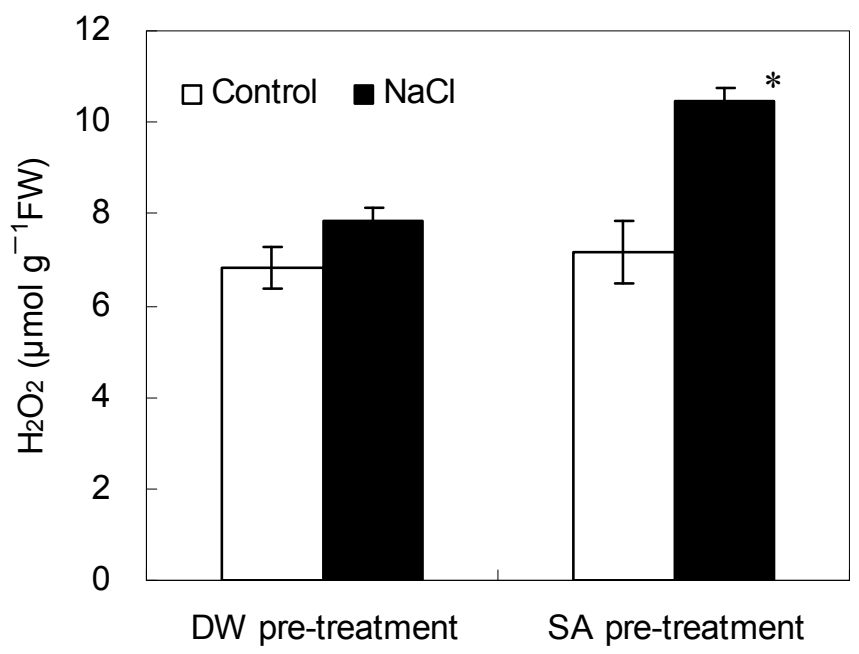

Fig. 4 

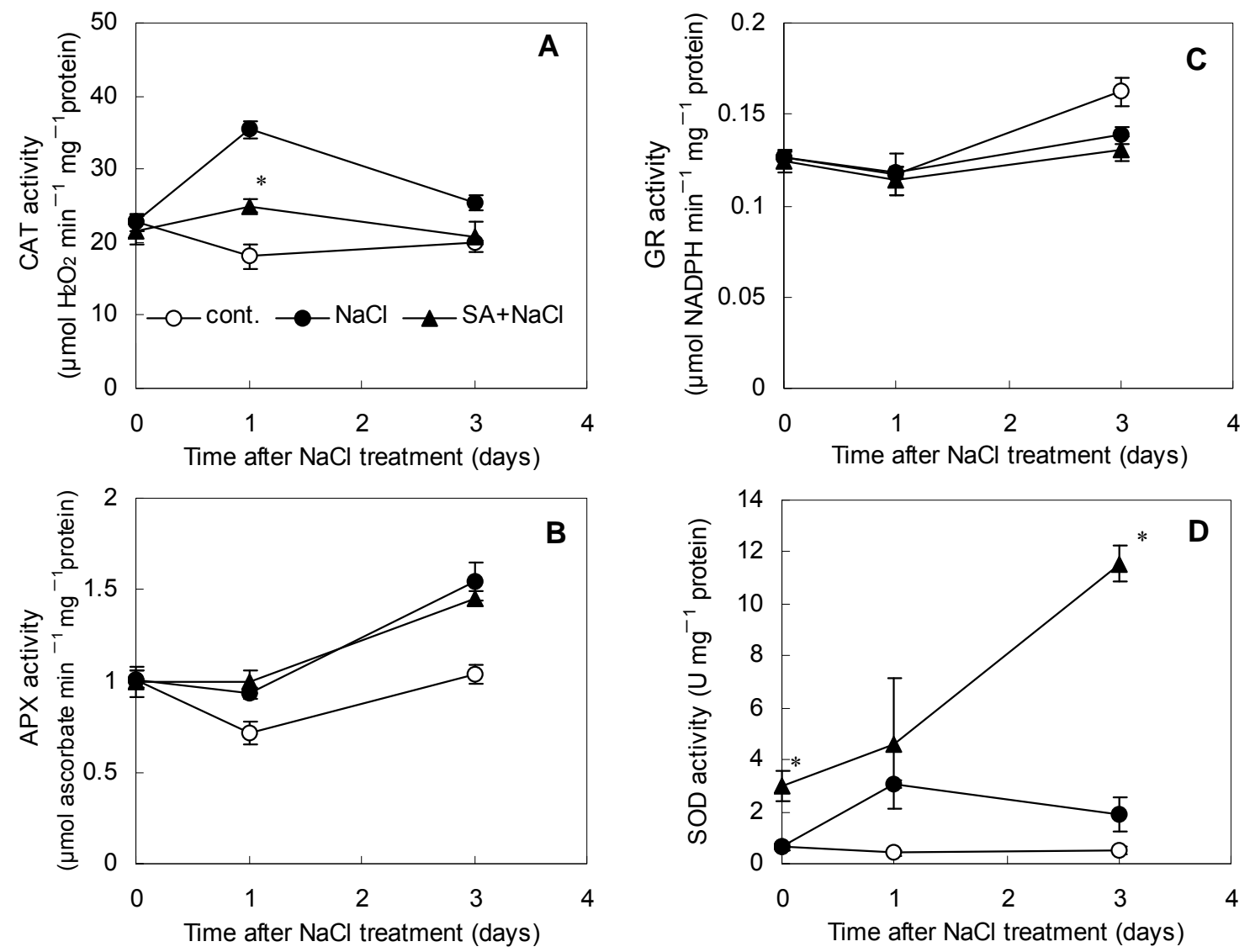

Fig. 5 